\title{
The Status of Women: Conceptual and Methodological Issues in Demographic Studies
}

\author{
Karen Oppenheim Mason \\ University of Michigan
}

\begin{abstract}
This paper explores several conceptual problems in social demographic studies of the status of women, including failure to recognize the multidimensionality of women's status and its variation across social "locations," the confounding of gender and class stratification systems, and the confounding of access to resources with their control. Also discussed are some generic problems in the measurement of female status, such as the sensitivity of particular indicators to social context, and the need to select consistent comparisons when judging the extent of gender inequality.
\end{abstract}

\section{INTRODUCTION}

This article aims to clarify the much-used but ill-defined term, "status of women," and to discuss some problems inherent in its measurement in demographic and other quantitative, macrosociological studies. As has been true in many academic disciplines, in demography the subject of women's status was, until recently, viewed as a "special" topic rather than one central to mainstream theories of demographic change. Although demographic researchers sometimes mentioned women's roles and status (e.g., Ridley, 1968), many statements about the determinants of fertility and mortality ignored these variables. This peripheral intellectual status no doubt in part reflected the functionalist and familistic cast of traditional demographic transition theory. As outlined by Coale (1973) and others, traditional demographic transition theory tended to focus on the interests and constraints of family units rather than those of the individuals within them. Although demographic transition theory recognized that women's labor force participation might motivate cou-

\footnotetext{
- This work was supported by the Population Sciences Division of the Rockefeller Foundation, who published an earlier version in a working paper entitled "The Status of Women: A Review of Its Relationships to Fertility and Mortality." I thank the reviewers for their excellent advice, Mary Claire Toomey for word processing, and Kathleen Duke for preparing the figure.
}

(C) 1986 by The Eastern Sociological Society. All rights reserved. 0884-8971/86/0102-0284\$1.50 
ples to limit fertility, this effect was based on the implications of women's work for the family's budget, rather than on its implications for women's freedom from the control of male family members. Even some recent theories of fertility behavior (e.g., the New Home Economics approach) share the assumption that husbands and wives reach decisions without conflict and that the wife's gainful employment is a component of the family's budget rather than a determinant of her domestic power.

Of course, not all past demographers ignored the topic of women's status. Beginning in the 1960s, a small group (e.g., Blake, 1965; Ridley, 1968; Dixon, 1975; Germain, 1975) argued that the status of women has important demographic implications. Only in the last five years, however, has this idea entered the mainstream of demographic thought. Currently, the status of women-or some related aspect of gender inequality - plays an important role in Caldwell's (1982) theory of wealth flows, in Cain's (1982) ideas about risk insurance and the fertility transition, and in the work of Dyson and Moore (1983), Safilios-Rothschild $(1980,1982)$ and others. Although the status of women has not become the central variable in most theories of the fertility transition, it has at least entered the mainstream of social demography.

\section{DEFINITIONS OF THE STATUS OF WOMEN}

Despite increased attention to the concept of female status, the meaning of this concept has remained unclear, and alternative definitions and terms have proliferated. Among the terms used in the social demographic literature are not only "status of women" (e.g., Dixon, 1978), but also "female autonomy" (Dyson and Moore, 1983), "patriarchy" (Cain et al., 1979), "rigidity of the sex stratification system" (Safilios-Rothschild, 1980), "women's rights" (Dixon, 1975) and "men's situational advantage" (Caldwell, 1981). All these terms refer, in part, to some aspect of gender inequality. Beyond this common focus on gender inequality, however, there are great variations in definitions of "female status" and related terms. Some authors (e.g., Epstein, 1982) focus on women's prestige, that is, on the respect or esteem (or lack thereof) that is accorded to women by virtue of their gender (rather than for some other reason, such as the social standing of their family). Other authors (e.g., Dyson and Moore, 1983) focus on women's power or freedom from control by others, especially within the family or household. For example, Cain et al. (1979:406) define "patriarchy" as "a set of social relations with a material base that enables men to dominate women patriarchy describes a distribution of power and resources within families such that men maintain power and control of resources, and women are powerless and dependent on men." 
Finally, as the quotation from Cain et al. suggests, many students of female status also focus on women's control of resources, either material or nonmaterial. Thus, Dixon (1978:6), after noting that the status of women is "an elusive concept," defines it as "the degree of women's access to (and control over) material resources (including food, income, land, and other forms of wealth) and to social resources (including knowledge, power, and prestige) within the family, in the community, and in the society at large." Safilios-Rothschild (1980) also emphasizes the control of resources.

Despite the bewildering variety of specific terms and definitions, certain common threads can be seen. Most terms and definitions refer at least in part to gender inequality; most also focus on one of three basic dimensions of gender inequality, (1) prestige, (2) power, or (3) access to or control over resources. Unfortunately, recognizing this does not clarify all confusion about the meaning of female status or gender inequality. As Dixon notes, the concept remains elusive.

\section{SOURCES OF CONFUSION ABOUT THE MEANING OF THE STATUS OF WOMEN}

There are good reasons for the confusion that surrounds the concept of female status. Two general sources are: (1) the inherent complexity of gender inequality, in particular, the fact that the sexes typically are unequal on more than one dimension and in more than one social situation; and (2) a weak grasp of stratification theory by some writers that has led to a confounding of class and gender stratification and to confusion between access to resources and control of them. ${ }^{1}$ I discuss each of these problems in turn.

\section{Multidimensionality}

There is more than one dimension on which it is theoretically possible for the sexes to be unequal. Several discussions of female status imply, however, that although the status of women may be conceptually divisible into separate dimensions, it is empirically a single dimension (e.g., Safilios-Rothschild, 1980). In other words, the correlations between different dimensions of gender inequality may be so strong that it makes sense to talk about "the" status of women. Similarly, there are many different kinds of resources that either men or women can con-

\footnotetext{
'Also to blame for the confusion surrounding the status of women is a third factor that will be ignored here. This is the disagreement about stratification systems endemic in the field of sociology, especially the disagreement between the Marxist and functionalist traditions.
} 
trol, hence many possible sources of male-female power differences. In particular historical situations, however, the control of certain resources (e.g., productive resources such as land and draft animals) may give those who control them so much power that they are able to gain control of all other resources.

Fortunately, the question of whether there is any such thing as "the" status of women has already been studied systematically. Probably the most exhaustive study was conducted by Whyte (1978), who examined a sample of ninety-three preindustrial cultures found in the Human Relations Area File. Whyte returned to the original ethnographic sources and coded each culture on several dozen possible indicators of female status. He then took the fifty-two most promising indicators and correlated them across the ninety-three cultures, performing a cluster analysis in order to ascertain whether more than one cluster existed. The result was nine significant and distinct clusters. In other words, societies in which women were powerless or of low status in one area did not necessarily show women to be powerless or of low status in other areas. Whyte thus concluded that there is no such thing as "the" status of women. Gender inequality is empirically as well as conceptually a multidimensional phenomenon.

Whyte's results also fit with impressionistic evidence about the position of women in different societies. For example, the historical literature on the rise of the cult of domesticity in early nineteenth century America (e.g., Smith, 1973; Degler, 1980) suggests that the creation of an ideology of separate spheres may have increased women's economic dependency on their husbands at the same time that it increased their prestige and domestic authority by giving them an area of competency and expertise-namely, childrearing and the moral upkeep of the family-that they formerly lacked. A similar picture of gender inequality varying across dimensions emerges in descriptions of West African women, who are sometimes cited as being unusual for their economic independence, but who do not appear to have prestige or legal rights markedly superior to those of African women not engaged in independent economic activities (Ware, 1977; Safilios-Rothschild, 1980). ${ }^{2}$

Failure to recognize that women's power, prestige and wealth do not necessarily rise and fall together may explain several controversies

\footnotetext{
${ }^{2}$ Also consistent with the view that the status of women is multidimensional is Oppong's (1983) framework for analyzing women's roles and fertility. Oppong suggests that women in developing countries typically enact seven basic roles (maternal, conjugal, domestic, kin, occupational, community and individual), the relative satisfactions and resources accruing to them via each of these roles potentially affecting their fertility. Although Oppong focuses on roles, rather than on dimensions of gender inequality, her assertion that women enact multiple roles-with varying satisfactions and resources available from each rolereinforces the point that gender inequality is multidimensional.
} 
in the literature. For example, whether the institution of purdah (female seclusion) enhances or detracts from women's status has been much debated. Many scholars have argued that seclusion lowers women's status by depriving them of opportunities to engage in income-generating activities (e.g., Youssef, 1982; Cain et al., 1979). Others, however, (Dixon, 1978; Epstein, 1982; Safilios-Rothschild, 1980) argue that

the often-discussed, so-called "greater freedom" of poor Muslim women in being able to avoid seclusion and to work represents nothing more than the husband's (and the entire family's) decision that her contributions are needed so that the social status attached to "purdah" has to be sacrificed (Safilios-Rothschild, 1980:193).

There are several possible explanations for these diametrically opposed views, some of which are discussed below. Relevant here, however, is the difference between purdah's effects on prestige (which are said by some authors to be positive) and its effects on power or resources (argued by Youssef and others to be negative). ${ }^{3}$

Although gender inequality is a multidimensional phenomenon, in models of fertility or mortality determination only one aspect of gender inequality may turn out to be important. This is in fact the view implicit in several approaches to the demographic transition, including Caldwell's (1979, 1981, 1983), Cain's (1982; Cain et al. 1979), Lesthaeghe's (1980), and Dyson and Moore's (1983). In this view (illustrated in Figure 1), three central assumptions are made. First, the extent of men's control over women within the bousebold is assumed to be the immediate determinant of demographic phenomena. The household is the primary locus where decisions affecting fertility and mortality are made, and in most agrarian societies, the household is where resources are generated and redistributed, hence, where individual "life chances" are determined.

Second, the control of women by male household members is itself assumed to reflect the sexes' relative control of material and social resources. The sexes' relative control of resources is in turn assumed to reflect extra-familial economic and kinship institutions, especially norms determining the sexual division of labor and the patterns of exchange associated with marriage and death.

Third, this view treats prestige as epiphenomenal (e.g., Dyson and

\footnotetext{
${ }^{3}$ Whether the prestige that accompanies the seclusion of women devolves primarily upon the woman herself or instead upon her family is not entirely clear. If it is families who benefit from women's seclusion rather than women per se, then Youssef and others may be correct in emphasizing that greater gender inequality accompanies purdah. This is one of several examples of possible confusion between class or caste status and gender status to be found in the literature. This problem is discussed below.
} 


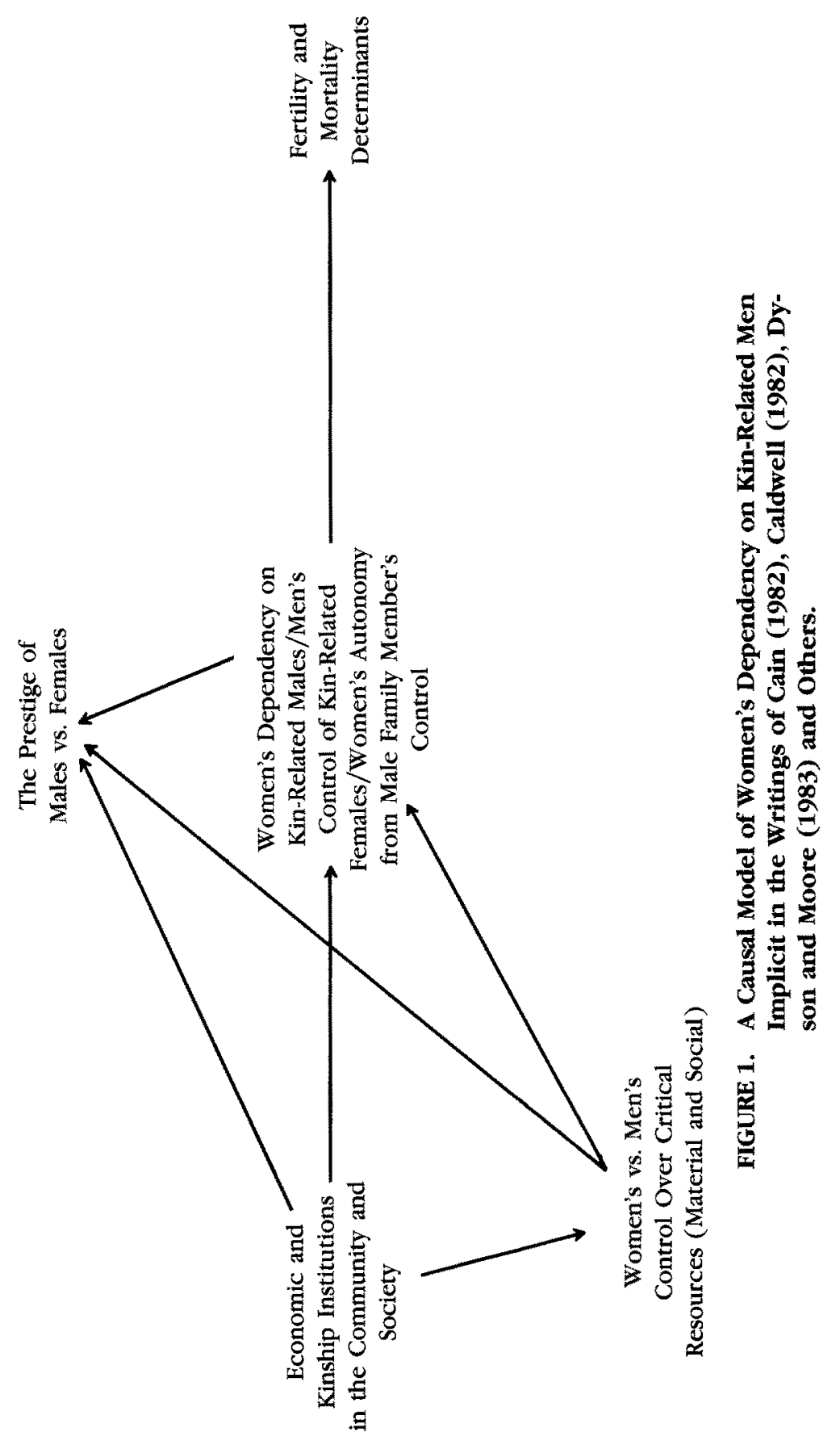


Moore, 1983). Prestige may be influenced by the material inequality of the sexes and may in turn reinforce this inequality, but it is not regarded as an important cause of either material or domestic inequality. ${ }^{4}$

This view thus provides a coherent model of how the different dimensions of gender inequality are related to each other and in turn influence fertility and mortality. While it does not deny the existence of different dimensions of gender inequality, it argues for a rank-ordering among them as determinants of fertility and mortality. Although this approach has considerable appeal, whether it is supported empirically remains to be determined. Contrary to what this model argues, kinship institutions may be only weakly linked to gender inequality in the control of material resources; control of these resources may be only weakly linked to the extent of women's autonomy within the household; and women's household autonomy may be only weakly linked with fertility or mortality. Studies that estimate the strength of the links shown in Figure 1 would be useful.

\section{Multiple Locations}

The concept of female status is complex not only because gender inequality is multidimensional, but also because it occurs in more than one social "location." Gender inequality can vary across the units of social organization in which the sexes interact, such as the household, the neighborhood, the community, or the voluntary association. Just as women's power, prestige or wealth may be weakly intercorrelated, so, too, their power or prestige in the household may be weakly related to their power or prestige in the community. Indeed, the ethnographic literature suggests that women who have little say in community or national organizations often have more say in the neighborhood or kin network, and even more say within the household (although there are societies where women's power and prestige are low in all spheres). This suggests that it may make sense to talk about "the" status of women only if a particular type of social unit is specified.

Another type of social location across which the degree of gender inequality may vary is the life cycle. As has been frequently noted, especially with regard to Asian cultures, the position of the new bride in family politics tends to be quite different from the position of her motherin-law, the new bride typically being powerless, while her mother-inlaw exercises considerable domestic control over other women and children. To be sure, whether the mother-in-law's power is "real" is

\footnotetext{
"As will be obvious to many readers, this model follows Marxian rather than functionalist assumptions. It thus deviates fundamentally from the traditional model of the demographic transition, which is basically functionalist in character (see Lesthaeghe, 1980).
} 
controversial (e.g., Safilios-Rothschild, 1982 vs. Caldwell, 1981). ${ }^{5}$ Regardless of the extent to which older women's domestic power derives from delegation, however, it appears to be greater than the new bride's. It may thus be necessary to distinguish women's power according to life cycle stage-or to distinguish social systems in which women have equally little power throughout the life span from those in which they gain power as they age.

\section{The Confounding of Gender and Class}

Most sociologists recognize that complex societies are typically structured by at least two independent systems of stratification (i.e., institutionalized systems of inequality). ${ }^{6}$ These are (1) a gender stratification system, that is, a system in which women and men are assigned distinct roles in the social division of labor and in consequence control different kinds or amounts of resources; and (2) a class or caste system, one in which bousebolds occupy distinct positions in the social division of labor and in consequence enjoy differential control over resources. ${ }^{7}$ The coexistence of more than one stratification system in a given society means that the socioeconomic position of any individual reflects his or her position in each system. Thus, a woman who is poor may be poor because she is a woman or because she is a member of a lowerclass household-or both.

In much of the demographic literature focused on the status of women, the distinction between gender and class stratification has unfortunately been ignored. Fertility or mortality has been linked not to the extent of gender inequality and, separately, to class position, but rather to women's net level of resources, regardless of whether that level reflects their position in the gender stratification system or in the class system.

This confounding of gender and class stratification tends to obfuscate the forces that influence fertility or mortality. For example, consider one important proximate determinant of mortality levels in Third World countries, nutritional level. In most peasant cultures, the extent of the family's land holdings-a basic mark of their class position-has

\footnotetext{
${ }^{5}$ That this power is rarely exercised over men is taken by some authors to indicate that it exists only so long as the men who delegate it continue to support the mother-in-law's authority.

${ }^{6}$ Most, perhaps all, societies also have a third stratification system, namely, one based on age (see Riley et al., 1972).

${ }^{7}$ Whether it is households or individuals who occupy positions in the class stratification system is in fact problematic, especially in industrial societies where, by definition, most production is carried out by units other than households. In most Third World countries, however, this is less problematic: economic production in these countries remains centered around households.
} 
a strong influence on the average nutritional level of household members. More land typically means more food and hence better average nutrition. In cultures where the gender system gives feeding priority to adult men, however, the nutritional status of women and children in relatively well-off peasant families may remain marginal because they are forced to consume what adult male family members leave behind once they have eaten their fill (e.g., Katona-Apte, 1975; Chen et al., 1981). In other words, in these cases, class interacts with gender in determin. ing nutritional and mortality levels.

The confounding of gender and class stratification is also unfor. tunate because it tends to obscure the appropriate level of analysis for studying the impact of gender inequality on fertility or mortality. Recognizing that women's net socioeconomic position reflects their position in two systems of stratification emphasizes the need to study gender inequality at the group rather than individual level. While systems of gender stratification may not be uniform within particular political units such as nation-states, they can only be called systems insofar as they are uniform for some aggregate. Understanding the impact of gender inequality on fertility or mortality therefore requires an analysis that compares groups differing in their gender stratification systems.

When women's net socioeconomic position becomes the focus, it is all too easy to think in terms of comparing individual women rather than social aggregates. Yet analysis at this level fails to make clear the impact of variation in gender inequality on fertility and mortality. For this reason, it is preferable to maintain the analytic distinction between gender and class position when studying the determinants of fertility or mortality. In the remainder of this discussion, I will use the term "status of women" to refer only to the position of women in the gender stratification system; in other words, to refer to their position relative to men's.

\section{Access to vs. Control of Resources}

Another problem in analysis of female status, fertility, and mortality involves the distinction between access to resources and the control of them. Merely having access to resources, i.e., the right to use or consume them if those who control them give their permission, is insufficient to generate control over one's environment. Control implies the ability to dispose of the resource while access implies only the right to use or consume it with the permission of those holding the right to dispose of it.

This distinction is especially important when studying gender systems because the typical arrangement between the sexes, especially in agrarian and early industrial societies, is for women to trade control of 
resources for access to them. In many Mediterranean, Asian, and Latin American countries today the enforced economic dependency of women on male kin arises from a system in which men control the household's resources but give women access to them (though not necessarily as much as the men themselves have). To say that women have "high status" because they have access to a high level of resources can therefore be misleading. If the social system deprives them of resource control, then their "status" is in fact likely to be low. In the long run, men are likely to be better off and have more power than women have.

Unfortunately, many discussions of female status and fertility or mortality have failed to heed the distinction between access and control and have thereby contributed to the confusion surrounding the status of women. Certain Third World social institutions, such as purdah (female seclusion) or the levirate (remarriage of widows to the husband's brother), are typically viewed by feminist scholars as lowering women's status, but other scholars view them as enbancing the position of women or at least not damaging it. For example, Burch (1983:951) argues that in "male-dominated" West African societies, the levirate "provides economic support and social standing for a woman who otherwise might have no acceptable social role," even though her ability to determine whom she marries-or whether she remarries at all-is clearly limited by this institution. What Burch seems to be saying is that the levirate helps women by giving them access to needed resources (including the status of wife). This obviously is not the same as arguing that it gives them control of resources, i.e., helps to equalize their power with men's. Arguments that purdah provides physical protection or prestige are similar. They usually do not claim that women gain control of critical resources by entering into seclusion, but rather that they gain access to resources via male family members.

Because control of resources ultimately means the ability to determine access, the relative resource control of women and men should be, in the long run, more critical than is their relative access at any given point in time. Studies concerned with the impact of women's status on demographic or social phenomena would be wise to focus on resource control.

\section{MEASURING FEMALE STATUS EMPIRICALLY}

Numerous empirical indicators of female status have been used or suggested for use in the demographic literature. Table 1 lists a sampling of the most commonly mentioned of these. In the absence of a specific hypothesis or research question about female status and fertility or mortality, specifying the weaknesses or strengths of particular empirical 
measures is difficult, although two recent United Nations documents have attempted to do just that (United Nations, $1984 \mathrm{a}$ and 1984b). Consequently, we focus here on four general problems that are among the most common that the measurement of female status entails.

\section{The Problem of Measuring a Poorly Defined Concept}

The first of these problems reflects the conceptual ambiguity that surrounds female status and the failure of many authors to adopt a clear definition of the concept. For example, Javillonar and her colleagues (1979:7-11) assert that four measurable quantities indicate the status of women in developing countries: (1) the extent to which there is early and universal female marriage, (2) the extent to which husbands have the arbitrary right to divorce a wife, (3) the extent to which marriages are arranged by the older generation, and, most important, they say, (4) the extent to which women participate in the labor force. Because Javillonar et al. offer no definition of female status, however, the adequacy of these four indicators is unclear.

\section{The Problem of Context Dependency}

The second problem in measuring female status arises because a given social practice or legal right may enhance women's prestige or autonomy in one context, but have the opposite effect in another. That is, combinations of circumstances, rather than a society's value on a single variable, are often what determine the extent of men's control over women or women's prestige compared to men's. Or, put differently, interaction effects tend to dominate main effects in the determination of gender inequality.

Instances in which particular social institutions have alternative meanings for gender inequality are rife. Take, for example, the institution of polygyny (multiple wives). Epstein (1982) describes Bangladeshi wives as "dreading" the possibility of their husband taking a second wife, but says Ivory Coast wives tolerate or even look forward to this prospect. In the Bangladeshi context, polygyny often means that a husband transfers his affection and economic support from the old wife to the new. In the Ivory Coast, however, where women are largely self-supporting, the arrival of a second wife often permits a division of labor among wives that increases each woman's ability to fulfill her economic and domestic goals. Thus, the meaning of this institution depends on

\footnotetext{
${ }^{8}$ Although neither report attempts to define the status or situation of women in the abstract, both present useful criticisms of existing social indicators on the situation of women and data collection efforts; both also provide valuable suggestions as to how to best use existing data and collect new data on women's situation.
} 
TABLE 1. Indicators of Female Status Commonly Used or Mentioned in the Social Demographic Literature

\begin{tabular}{lc}
\hline Indicator of Female Status & $\begin{array}{c}\text { Relationship to } \\
\text { Female Status }\end{array}$ \\
\hline
\end{tabular}

DEMOGRAPHIC INDICATORS

Female Minus Male Mortality Rates

Female Age at Marriage

Average Husband-Wife Age Difference

Parents' Preferences for Male Children

KINSHIP-FAMILY INDICATORS

Purdah (Female Seclusion)

Levirate (Enforced Marriage of Widows to

Husband's Brother)

$-(?)$

Polygyny (Multiple Wives)

Conjugal Family Households

Emphasis on Lineage

Female Property Inheritance

Village Exogamy of Females (Out-Marrying)

$+$

Patrilocal Post-Marital Residence

Dowry

Arranged Marriages

Cross-Cousin Marriages

Emphasis on Virginity of Brides

Pre- or Post-Marital Sexual Double Standard

Emphasis on Women's Sexuality, Youthfulness

Male Right to Divorce Wife Without Her Consent

Egalitarianness of the Husband-Wife Relationship

Male Feeding Priority

Extended-Kin Support for Widows and Divorcees

$-$

\section{ECONOMIC INDICATORS}

Female Employment "Opportunities"

Female Labor Force Participation

Exclusion of Women from Extra-Domestic Activities

Concentration of Women vs Men in Informal Economic

Sector

Occupational Segregation of the Sexes

Sex Differences in Wages or Earnings

Sex Differences in the Amount of Leisure Time

Female Education

Female Underemployment or Unemployment Rates

$-$

$-$

$-$

$-$

$+$

$-$

$-$

$-$

$-$

$+$

$-$

$+$

Women's Work "Commitment" (Measured Variously)

Women's Access to Credit

Women's Access to Non-Familial Supports

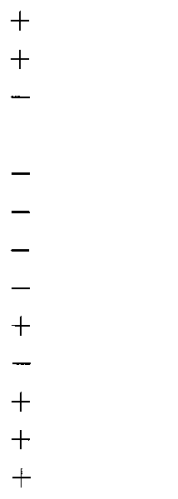


the extent to which wives are economically independent of their husbands as well as on cultural traditions about how husbands are to divide their attention and support among wives.

Among the most commonly used indicators of female status, especially in studies of fertility, are measures of women's labor-force participation or extra-domestic participation in economic production. $\mathrm{Al}$ though it is widely believed that such participation enhances women's domestic autonomy by giving them an independent source of income (e.g., Cain et al., 1979), the effects depend heavily on social context. For example, according to Cain et al. (1979), Indian women who participate in income-earning work seem to have more domestic autonomy than secluded Bangladeshi wives have. However, according to Jain (1970:46-47), overseas Indian women who work as wage laborers on Malia, ian rubber estates have very little domestic power, despite their employment. Indeed, among these estate workers, the tradition of male dominance is so strong that wives more or less automatically turn over all their wages to the husband, thereby giving him control of the family's most important material resource. The fact of women's employment does not appear to increase their autonomy.

Another example of context dependency involves the combination of village exogamy, patrilocal post-marital residence, and the maintenance of the joint household which is said by several scholars (e.g., Dyson and Moore, 1983) to result in a loss of autonomy for women during the prime childbearing years in settings such as North India and China. In these settings, it is claimed, a newly-married woman enters a household of strangers where she is powerless and without allies. Among the Ijaw of Nigeria, however, a similar combination of village exogamy, patrilocal residence, and the non-nuclear household has resulted in the creation of women's mutual aid associations that have in turn given women considerable domestic and community autonomy (Leis, 1974). Thus, even conditions that are widely-and seemingly logically - thought to undermine women's domestic power can, in some situations, have just the opposite effect.

\section{The Problem of an Appropriate Comparison}

Whether gender inequality is small or large obviously depends on the standard being used, that is, to what a given sex stratification system is being compared. Variation in the comparison implicitly used by different authors is yet another reason for the controversy surrounding such social institutions as purdah and the levirate. For example, when women in Moslem societies are compared with women in Western European or North American societies, the conclusion often is that purdah deprives women of autonomy. On the other hand, when these same 
women are compared with women in highly patriarchal non-Moslem societies, the conclusion often is the reverse: purdah does not deprive women of autonomy any more than a number of other patriarchal institutions do and may even provide women with security or prestige. Depending on the point of comparison chosen, a given measure of female status can lead to different conclusions.

\section{The Problem of Measures with Multiple Meanings}

The final generic problem in measuring female status involves the multiple meanings of certain widely available and frequently used indicators of female status, such as educational attainment level. Because these indicators often tap factors other than the status of women that are likely to influence fertility or mortality, their use can produce results that are difficult to interpret. For example, does a higher level of female education lead to lower fertility or infant mortality because it gives women the resources to stand up to their husbands or mothers-in-law? Or does it have this effect because it allows women to learn about modern fertility control methods or effective health care? Unfortunately, for many forms of research, variables that indicate more than one underlying construct are often the only or the most reliably measured indicators of female status available. This means that research on female status and fertility or mortality often suffers from ambiguous measurement.

\section{CONCLUSIONS}

This brief discussion of some of the complexities surrounding the definition and measurement of the status of women should make clear that the phenomenon of gender inequality is inherently complex. Men and women are typically unequal in a number of important respects, and the nature or extent of their inequality usually varies across these dimensions and according to social setting and life cycle stage. For this reason, attempts to relate "the" status of women to demographic or other social phenomena run the risk of seriously distorting reality. There is more than one aspect of female status, and each aspect may relate to fertility or mortality quite differently.

Earlier comments have already suggested strategies likely to improve the quality of work on the status of women in relation to fertility or mortality. Some examples are: maintaining the distinction between gender and class inequality; focusing on women's vs. men's control of resources; being sensitive to the distinctive interplay of variables in different social contexts; and using a consistent set of comparisons.

Two additional strategies may help clarify the relationship of gender inequality to demographic phenomena in future studies. The first is 
to avoid using the term "status of women" and to speak instead in terms of gender inequality, or better still, specific types of gender inequality (e.g., the extent of men's control over their wives). The term "status of women," when used to refer to gender inequality (as it usually is) presents a regrettably distorted picture of social reality, since it treats men as the reference point, and women as the "other" that deviates from this reference. "Gender inequality" provides a more even-handed and accurate description of the discrepancies in power, prestige and control of resources between the sexes that exist in most human populations. Terms such as "gender inequality" also are preferable because they avoid the potential confusion between gender and class or caste stratification noted earlier. "Status of women" can-indeed, probably should-refer to differences among women in power, prestige or resources, rather than to inequality between the sexes.

The other strategy likely to improve our understanding of gender inequality in relation to fertility or mortality is to relate such inequality to specific demographic variables, and develop theories that make clear why and how gender inequality causes or is caused by these variables. Focusing on a specific question, such as how gender inequality influences female age at first marriage or infant and child mortality, is far more likely to indicate which aspects of gender inequality, under which circumstances and in which social settings, are likely to be important than is a general discussion of the nature of gender inequality and its impact on demographic behaviors. This is precisely what Blake (1972), Cain (1982), Caldwell (1982), Dyson and Moore (1983) and others have attempted to do in recent years. Further elaboration of their ideas is much needed, as are empirical tests.

There can be little question that gender inequality is potentially important for demographic (and other social) phenomena. In a world where women bear children and shoulder the major responsibility for rearing them, their autonomy from male control during the prime childbearing years, the respect they are accorded by virtue of being women, and the types and amounts of resources they control, should be critical for their motives and choices, hence, for reproductive patterns and the determinants of mortality among infants, children and women. The demographic transition has been described as a social revolution. It is high time we gave full recognition to the role of women in this and other modern revolutions.

\section{REFERENCES}

Blake, Judith

1965 "Demographic science and the redirection of population policy." Journal of Chronic Diseases
18(November):1181-1200.

1972 "Coercive pronatalism and American population policy." In R. Parke, Jr. and C. F. Westoff (eds.), The 
Commission on Population Growth and the American Future Research Reports, Volume Six, Aspects of Population Growth Policy:81-109. Washington, DC: U.S. Government Printing Office.

Burch, Thomas $\mathbf{K}$.

1983 "The impact of forms of families and sexual unions and dissolution of unions on fertility." In R. A. Bulatao and R. D. Lee et al. (eds.), Determinants of Fertility in Developing Countries:948-970. Washington, DC: Cain, Mead National Academy Press.

1982 "Perspectives on family and fertility in developing countries." Population Studies 36(July):159-175.

Cain, Mead, Syeda Rokeya Khanam and Shamsun Nahar

1979 "Class, patriarchy, and women's work in Bangladesh." Population and Development Review 5(September):405-438.

Caldwell, John C.

1979 "Education as a factor in mortality decline: An examination of Nigerian data." Population Studies 33 (November):395-413.

1981 "The mechanisms of demographic change in historical perspective." Population Studies 35(March):5-27.

1982 Theory of Fertility Decline. London: Academic Press.

1983 "Direct economic costs and benefits of children." In R. A. Bulatao and R. D. Lee et al. (eds.), Determinants of Fertility in Developing Countries: 370-397. Washington, DC: National Academy Press.

Chen, Lincoln C., Emdadul Huq and Stan D'Souza

1981 "Sex bias in the family allocation of food and health care in rural Bangladesh." Population and Development Review 7(March):55-70.

Coale, Ansley J.

1973 "The demographic transition." In International Union for The Scientific Study of Population (ed.), International Population Conference, Vol. I:53-72.
Degler, Carl N.

1980 At Odds: Women and the Family in America from the Revolution to the Present. Oxford: Oxford University Press.

Dixon, Ruth B.

1975 "Women's rights and fertility." Reports on Population/Family Planning, No. 17 ( January).

1978 Rural Women at Work: Strategies for Development in South Asia. Baltimore: Johns Hopkins University Press.

Dyson, Tim and Mick Moore

1983 "On kinship structure, female autonomy, and demographic behavior in India." Population and Development Review 9(March):35-60.

Epstein, T. Scarlett

1982 "A social anthropological approach to women's roles and status in developing countries: The domestic cycle." In R. Anker, M. Buvinic and N. H. Youssef (eds.), Women's Roles and Population Trends in the Third World:151-170. London: Croom Helm.

\section{Germain, Adrienne}

1975 "Status and roles of women as factors in fertility behavior: A policy analysis." Studies in Family Planning 6( July):192-200.

Jain, Ravindra $\mathbf{K}$.

1970 South Indians on the Plantation Frontier in Malaya. New Haven, CT: Yale University Press.

Javillonar, Gloria, Laurie Zivetz, Susan Thompson and Janet Griffith

1979 Rural Development, Women's Roles and Fertility in Developing Countries: Review of the Literature. Durham, NC: Research Triangle Institute and South East Consortium for International Development.

\section{Katona-Apte, Judit}

1975 "The relevance of nourishment to the reproductive cycle of the female in India." In Dana Raphael (ed.), Leis, Nancy $B$. Being Female. The Hague:Mouton.

1974 'Women in groups: Ijaw women's associations." In M. Z. Rosaldo and 
L. Lamphere (eds.), Woman, Culture, and Society:223-242. Stan. ford, CA: Stanford University Press.

\section{Lesthaeghe, Ron}

1980 "On the control of human reproduction." Population and Development Review 6:527-548.

\section{Oppong, Christine}

1983 "Women's roles, opportunity costs, and fertility." In R. A. Bulatao and R. D. Lee et al. (eds.), Determinants of Fertility in Developing Countries:439-473. Washington, $\mathrm{DC}: \mathrm{Na}$ tional Academy Press.

Ridley, Jeanne Clare

1968 "Demographic change and the roles and status of women." Annals of the American Academy of Political and Social Science 375:15-25.

Riley, Matilda White, Marilyn Johnson and Anne Foner

1972 Aging and Society, Vol. 3: A Sociology of Age Stratification. New York: Russell Sage Foundation.

Safilios-Rothschild, Constantina

1980 "A class and sex stratification theoretical model and its relevance for fertility trends in the developing world." In C. Hoin and R. Machensen (eds.), Determinants of Fertility Trends: Theories Re-Examined: 189-202. Liege: Ordina Editions.

1982 "Female power, autonomy and demographic change in the Third World." In R, Anker, M. Buvinic and N. H. Youssef (eds.), Women's Roles and Population Trends in the Third World:117-132. London: Croom Helm.

Smith, Daniel Scott

1973 "Family limitation, sexual control, and domestic feminism in Victorian America." Feminist Studies 1(WinterSpring):40-57.

\section{United Nations}

$1984 a$ "Compiling social indicators on the situation of women." United Nations, Department of International Economic and Social Affairs, Statistical Office, and International Research and Training Institute for the Advancement of Women, Studies in Methods, Series F, No. 32.

198 b "Improving concepts and methods for statistics and indicators on the situation of women." United Nations, Department of International Economic and Social Affairs, Statistical Office, and International Research and Training Institute for the Advancement of Women, Studies in Methods, Series F, No. 33.

Ware, Helen

1977 "Women's work and fertility in Africa." In S. Kupinsky (ed.), The Fertility of Working Women:1-34. New York: Praeger.

Whyte, Martin King

1978 The Status of Women in Preindustrial Societies. Princeton, NJ: Princeton University Press.

\section{Youssef, Nadia $H$.}

1.982 "The interrelationships between the division of labour in the household, women's roles and their impact on fertility." In R. Anker, M. Buvinic and N. H. Youssef (eds.), Women's Roles and Population Trends in the Third World:173-201. London: Croom Helm. 